\title{
Major histocompatibility complex class I expression impacts on patient survival and type and density of immune cells in biliary tract cancer
}

\author{
Benjamin Goeppert ${ }^{\star}, 1$, Lena Frauenschuh ${ }^{1}$, Manuela Zucknick ${ }^{2}$, Stephanie Roessler ${ }^{1}$, Arianeb Mehrabi ${ }^{3}$, \\ Mohammadreza Hafezi ${ }^{3}$, Albrecht Stenzinger ${ }^{1}$, Arne Warth ${ }^{1}$, Anita Pathil ${ }^{4}$, Marcus Renner ${ }^{1}$, Peter \\ Schirmacher ${ }^{1}$ and Wilko Weichert ${ }^{1,5,6,7}$
}

${ }^{1}$ Institute of Pathology, University Hospital Heidelberg, Heidelberg D-69120, Germany; ${ }^{2}$ Division of Biostatistics, German Cancer Research Center (DKFZ), Heidelberg D-69120, Germany; ${ }^{3}$ Department of General, Visceral and Transplantation Surgery, University Hospital Heidelberg, Heidelberg D-69120, Germany; ${ }^{4}$ Department of Internal Medicine IV, Gastroenterology and Hepatology, University Hospital Heidelberg, Heidelberg D-69120, Germany; ${ }^{5}$ National Center for Tumour Diseases (NCT), Heidelberg D-69120, Germany; ${ }^{6}$ Institute of Pathology, Technical University Munich D-81675, Munich, Germany and ${ }^{7}$ German Cancer Consortium (DKTK)

Background: Biliary tract cancers (BTC) are rare malignant tumours with a poor prognosis. Previously, we have presented a detailed characterisation of the inflammatory infiltrate in BTC. Here, we analysed the impact of the expression of major histocompatibility complex class I (MHC I) on patient survival and the quantity, as well as the quality of tumour-infiltrating immune cell types in BTC.

Methods: MHC I expression was assessed semi-quantitatively in 334 BTC, including extrahepatic $(n=129)$ and intrahepatic cholangiocarcinomas $(n=146)$, as well as adenocarcinomas of the gallbladder $(n=59)$. In addition, 71 high-grade biliary intraepithelial lesions (BillN 3) were included. Results were correlated with data on antitumour inflammation and investigated with respect to their association with clinicopathological variables and patient survival.

Results: BTC showed a wide spectrum of different $\mathrm{MHC}$ I expression patterns ranging from complete negativity in some tumours to strong homogenous expression in others. In BillN 3, significantly higher MHC I expression levels were seen compared to invasive tumours $(P=0.004)$. Patients with strong tumoural $\mathrm{MHC}$ I expression had a significantly higher overall survival probability (median survival benefit: 8 months; $P=0.006$ ). $\mathrm{MHC}$ I expression strongly correlated with the number of tumour-infiltrating T-lymphocytes $\left(\mathrm{CD} 4^{+}\right.$and $\left.\mathrm{CD} 8^{+}\right)$and macrophages.

Conclusions: Differences of $\mathrm{MHC}$ I expression predict patient outcome and show correlations with specific components of the inflammatory infiltrate in BTC. These findings contribute to a better understanding of immune response and immune escape phenomena in cholangiocarcinogenesis.

Biliary tract cancers (BTC) are a diverse group of tumours that can be classified into three major subtypes: cholangiocarcinomas of intrahepatic (ICC) and extrahepatic (ECC) origin and adenocarcinomas of the gallbladder (GBAC). For BTC patients with locally advanced or metastatic disease, the prognosis is poor with a median survival of $<1$ year (Hezel et al, 2010). Common therapeutic options include surgery and chemotherapy, but because BTC patients often present with advanced disease not amenable to

*Correspondence: Dr B Goeppert; E-mail: benjamin.goeppert@med.uni-heidelberg.de

Received 20 February 2015; revised 19 July 2015; accepted 5 August 2015; published online 13 October 2015

(c) 2015 Cancer Research UK. All rights reserved 0007-0920/15 
surgery and current chemotherapeutic regimens are rather ineffective, novel treatment options are of paramount importance (Patel, 2011).

Tumour cells are often surrounded by infiltrating inflammatory cells, particularly lymphocytes and macrophages (Smyth et al, 2006) and there is compelling evidence that tumour-infiltrating T-lymphocytes have a favourable effect on patient survival in several malignant tumours, including colorectal (Galon et al, 2006; Mlecnik et al, 2011), ovarian (Zhang et al, 2003), breast (Mahmoud et al, 2011) and pancreatic (Fukunaga et al, 2004) cancer. By investigating a large cohort of BTC, we were able to show a favourable prognostic effect of tumour-infiltrating T-lymphocytes in ECC and GBAC, but not in ICC (Goeppert et al, 2013).

Tumour antigens drive the development of tumour-specific adaptive immune responses (Boon et al, 1994). Specifically, CD8 ${ }^{+}$ T-lymphocytes attack tumour cells presenting tumour-associated antigen peptides via major histocompatibility complex type I (MHC I) molecules on their surface by producing interferon gamma. Interferon gamma-dependent mechanisms of tumour cell cytostasis and killing comprise cell cycle inhibition, apoptosis, angiostasis and induction of antitumourigenic activity of macrophages (Dunn et al, 2004). MHC I molecules are constitutively expressed on normal epithelial cells. Changes of MHC I expression are often observed in tumours and downregulation of MHC I has been described as a frequent feature in various tumour types, including pancreatic adenocarcinoma (Ryschich et al, 2005; Rodriguez et al, 2007; Campoli and Ferrone, 2008; Du and Wang, 2011). In the neoplastic setting, MHC I is regarded to exert a central role in the regulation of $\mathrm{CD}^{+}$cytotoxic T-lymphocyte recognition of carcinoma-specific antigens, and loss of MHC I expression has been suggested as one major escape pathway for the evasion of $\mathrm{CD}^{+}$cytotoxic T-lymphocyte surveillance. In several tumour types, including colorectal cancer, it has been reported by others and us that downregulation of MHC I expression is more frequently observed in metastatic stages and poorly differentiated tumours (Kasajima et al, 2010; Du and Wang, 2011).

As the role of MHC I in cholangiocarcinogenesis has not yet been examined systematically, we focused in this study on the impact of MHC I expression on quantity and quality of the tumour-infiltrating immune cell infiltrate, as well as on associations of MHC I expression with patient survival in BTC. This approach extends our current knowledge of the interaction between the immune system and BTC, and provides a solid translational resource for both future functional studies and clinical trials.

\section{MATERIALS AND METHODS}

Clinicopathological characteristics of BTC patients. Tissue samples from 334 patients (median age: 64.2 years) who underwent bile duct and/or liver surgery at the University Hospital Heidelberg between 1995 and 2010 were included in our cohort. Only patients with primary adenocarcinomas of the biliary tract and without other known malignancies at the time of diagnosis were included. Our BTC cohort comprised of 129 ECC (93 perihilar and 36 distal), 146 ICC and 59 GBAC. In addition, 71 high-grade intraepithelial lesions (BilIN 3) were included; 59 of these were corresponding to invasive BTC samples of our cohort. Patients who received neoadjuvant radiochemotherapy were excluded. Survival data was available for 302 patients (Supplementary Table 1). Tumours were restaged according to the 7 th TNM Classification of Malignant Tumours and classified after the World Health Organization tumour classification system (Bosman et al, 2010). Clinicopathological data of the complete BTC study cohort are provided in Table 1. Clinicopathological data stratified
Table 1. MHC I expression in BTC stratified by

clinicopathological parameters

\begin{tabular}{|c|c|c|c|c|}
\hline & Number (\%) & MHC I & MHC I & $P$-value \\
\hline & & $\begin{array}{c}\text { IRS 0-6 } \\
\text { (number (\%)) }\end{array}$ & $\begin{array}{c}\text { IRS 8-12 } \\
\text { (number (\%)) }\end{array}$ & $\chi^{2}$ test \\
\hline All cases & 334 (100) & $175(52.4)$ & 159 (47.6) & \\
\hline \multicolumn{5}{|l|}{ Age } \\
\hline $\begin{array}{l}64-92 \text { years } \\
31-64 \text { years }\end{array}$ & $\begin{array}{l}169(50.6) \\
165(49.4)\end{array}$ & $\begin{array}{l}90(53.3) \\
85(51.5)\end{array}$ & $\begin{array}{l}79(46.7) \\
80(48.5)\end{array}$ & 0.835 \\
\hline \multicolumn{5}{|l|}{ Sex } \\
\hline $\begin{array}{l}\text { Male } \\
\text { Female }\end{array}$ & $\begin{array}{l}163(48.8) \\
171(51.2)\end{array}$ & $\begin{array}{l}78(47.9 \%) \\
97(56.7 \%)\end{array}$ & $\begin{array}{l}85(52.1) \\
74(43.3)\end{array}$ & 0.13 \\
\hline
\end{tabular}

\section{BTC subgroups}

\begin{tabular}{|l|c|c|c|c|}
\hline ICC & $146(43.7)$ & $85(58.2)$ & $61(41.8)$ & 0.118 \\
ECC & $129(38.6)$ & $59(45.7)$ & $70(54.3)$ & \\
GBAC & $59(17.7)$ & $31(52.5)$ & $28(47.5)$ & \\
\hline
\end{tabular}

\begin{tabular}{|c|c|c|c|c|}
\hline \multicolumn{5}{|c|}{ Histology subgroups } \\
\hline Ductal & $274(82)$ & $146(53.3)$ & $128(46.7)$ & 0.187 \\
\hline Papillary & 22 (6.6) & $8(36.4)$ & $14(63.6)$ & \\
\hline Mucinous & $8(2.4)$ & $3(37.5)$ & $5(62.5)$ & \\
\hline Intestinal & $10(3)$ & $4(40)$ & $6(60)$ & \\
\hline Other & $20(6)$ & $14(70)$ & $6(30)$ & \\
\hline \multicolumn{5}{|c|}{ UICC stage } \\
\hline 1 & $38(14.2)$ & $15(39.5)$ & $23(60.5)$ & \multirow[t]{4}{*}{0.074} \\
\hline 2 & $67(25.1)$ & $32(47.8)$ & $35(52.2)$ & \\
\hline 3 & $71(26.6)$ & $33(46.5)$ & $38(53.5)$ & \\
\hline 4 & $91(34.1)$ & $56(61.5)$ & 35 (38.5) & \\
\hline \multicolumn{5}{|l|}{ pT } \\
\hline T1 & 73 (21.9) & $40(54.8)$ & $33(45.2)$ & \multirow[t]{4}{*}{0.474} \\
\hline $\mathrm{T} 2$ & 131 (39.2) & $62(47.3)$ & 69 (52.7) & \\
\hline T3 & 103 (30.8) & $59(57.3)$ & $44(42.7)$ & \\
\hline T4 & $27(8.1)$ & $14(51.9)$ & $13(48.1)$ & \\
\hline \multicolumn{5}{|l|}{$\mathrm{pN}$} \\
\hline NO & $118(45.6)$ & $53(44.9)$ & $65(55.1)$ & \multirow[t]{2}{*}{0.153} \\
\hline N1 & $141(54.4)$ & 77 (54.6) & $64(45.4)$ & \\
\hline \multicolumn{5}{|l|}{ M } \\
\hline MO & 315 (94.3) & $161(51.1)$ & 154 (48.9) & \multirow[t]{2}{*}{0.094} \\
\hline M1 & $19(5.7)$ & $14(73.7)$ & $5(26.3)$ & \\
\hline \multicolumn{5}{|c|}{ G } \\
\hline G1 & $18(5.4)$ & $5(27.8)$ & $13(72.2)$ & \multirow[t]{3}{*}{0.05} \\
\hline G2 & $228(68.3)$ & 118 (51.8) & $110(48.2)$ & \\
\hline G3 & $88(26.3)$ & $52(59.1)$ & $36(40.9)$ & \\
\hline \multicolumn{5}{|c|}{$\mathrm{L}$} \\
\hline LO & $154(46.1)$ & $76(49.4)$ & 78 (50.6) & \multirow[t]{2}{*}{0.357} \\
\hline L1 & $180(53.9)$ & $99(55)$ & $81(45)$ & \\
\hline \multicolumn{5}{|c|}{ V } \\
\hline V0 & $238(71.3)$ & $118(49.6)$ & $120(50.4)$ & \multirow[t]{2}{*}{0.133} \\
\hline V1 & $96(28.7)$ & $57(59.4)$ & $39(40.6)$ & \\
\hline \multicolumn{5}{|l|}{$\mathrm{Pn}$} \\
\hline $\mathrm{PnO}$ & $268(80.2)$ & $144(53.7)$ & $124(46.3)$ & 0.397 \\
\hline Pn1 & $66(19.8)$ & $31(47)$ & $35(53)$ & \\
\hline \multicolumn{5}{|c|}{$\begin{array}{l}\text { Abbreviations: } \mathrm{BTC}=\text { biliary tract cancer; } \mathrm{ECC}=\text { extrahepatic cholangiocarcinoma; } \mathrm{GBAC}= \\
\text { adenocarcinoma of the gallbladder; } \mathrm{ICC}=\text { intrahepatic cholangiocarcinoma; } \mathrm{IRS}=\text { immunoreactive } \\
\text { score; } \mathrm{MHC} \mathrm{I}=\text { major histocompatibility complex class I; } \mathrm{UICC}=\text { Union for International Cancer } \\
\text { Control. P-values were calculated by } \chi^{2} \text { test. }\end{array}$} \\
\hline
\end{tabular}

for the BTC subtypes are provided in Supplementary Tables 2-4. The use of the tissue for this study was approved by the institutional ethics committee (206/05).

Tissue microarray construction. From all 334 BTC, $3 \mu \mathrm{m}$ sections were cut and stained with H\&E. Representative areas from the tumour center and invasive margins were marked by two pathologists with a special expertise in BTC pathology (BG and 
WW). For each case, tumour tissue cores ( $1.5 \mathrm{~mm}$ diameter) from the selected representative tumour areas were punched out of the sample tissue blocks and embedded into a new paraffin array block using a tissue microarrayer (Beecher Instruments, Woodland, CA, USA).

Immunohistochemistry and tissue microarray evaluation. For the detection of MHC I, a monoclonal mouse IgG antibody directed against MHC I (clone number EMR8-5; dilution 1:5000; MBL, Nagoya, Japan) was used. This antibody detects human HLA class I (HLA-A, -B or -C). Staining was performed on an automated system (Discovery Ultra, Ventana, Tuscon, AZ, USA) following the manufacturer's instructions. MHC I antigen expression was scored by applying a semi-quantitative immunoreactive score (IRS) resulting in expression values ranging from 0 (no expression) to 12 (strong expression in more than $80 \%$ of tumour cells), as previously described (Goeppert et al, 2010). Briefly, staining intensity (0: no staining, 1: weak staining, 2: moderate staining, 3: strong staining), as well as percentage of immunostained cells ( 0 : no cells stained, $1:<10 \%$ of cells stained, 2: $10-50 \%$ of cells stained, $3: 51-80 \%$ of cells stained, $4:>80 \%$ of cells stained) are scored separately and the IRS for each individual case is calculated by multiplication of the intensity and the percentage score. Immunohistochemistry to detect and count specific inflammatory cells (CD4, CD8, CD20, CD68, CD117, Ki67) was performed as recently described (Goeppert et al, 2013). For technical reasons, some tissue microarray dots could not be evaluated (e.g. loss of tissue, staining artifacts). Therefore, the number of included cases for the analysis of MHC I expression and for the different immune cell types is slightly different.

Statistical analyses. Statistical analyses were performed with the statistical computing environment $\mathrm{R}$ version 3.1 and IBM SPSS STATISTICS version 19 (SPSS, Chicago, IL, USA). Spearman's rank order correlation was used to determine whether there was a positive or negative correlation between the degrees of tumourinfiltrating immune cells and proliferative activity. The significance of differences in the density of immune cells for differing tumour stages and other clinicopathological variables was assessed by Mann-Whitney $U$ test, Kruskal-Wallis test and $\chi^{2}$ test as indicated. Statistically significant trends associated with increasing UICC stages, tumour grades or T-stages were identified by JonkheereTerpstra and Cochran-Armitage trend test, respectively. Univariate survival analysis was performed for overall survival by calculating Kaplan-Meier curves. Significance of differences between the groups was assessed using log-rank test. For multivariate analysis, concordance regression was applied, representing a generalisation of Cox proportional hazards regression, which is robust to violations of the proportional hazards assumption. Test results with $P$-values $\leqslant 0.05$ were considered statistically significant. All tests were two-sided.

\section{RESULTS}

MHC I expression in BTC, BTC subtypes and in intraepithelial neoplastic lesions. MHC I immunohistochemistry showed a cytoplasmic and pronounced membranous staining pattern in tumour cells, stromal cells and immune cells; nuclear staining was not observed. BTC exhibited a wide spectrum of MHC I expression ranging from strong positivity in $>80 \%$ of tumour cells $($ IRS $=12$ ) to complete negativity in all tumour cells $($ IRS $=0)$. Representative pictures are shown in Figure 1. On the basis of this continuum of different MHC I expression patterns, tumours could be divided into two distinct expression groups: $47.6 \%(n=159)$ of tumours showed high (IRS $=8-12)$ MHC I expression and $52.4 \%(n=175)$ showed low (IRS $=0-6$ ) MHC I expression (Table 1 ). In addition, we applied a three-tier grouping algorithm, in which $19.2 \%$ of cases $(n=64)$ displayed strong (IRS $=9-12), 43.7 \%$ of cases $(n=146)$ moderate (IRS $=6-8)$ and $37.1 \%$ of cases $(n=124)$ weak (IRS $=0$ 4) MHC I expression. Differences in MHC I expression between the BTC subtypes were not observed (Supplementary Figure 1). Overall, intraepithelial neoplastic lesions (BilIN 3) showed significantly higher MHC I expression compared to invasive BTC $(P=0.004$; Figure 2$)$ with $67.6 \%(n=48)$ of BilIN 3 samples displaying high (IRS $=8-12$ ) MHC I expression and only $32.4 \%$ $(n=23)$ low (IRS $=0-6)$ MHC I expression. A matched-pair analysis $(n=56)$ of MHC I expression in BilIN 3 lesions directly
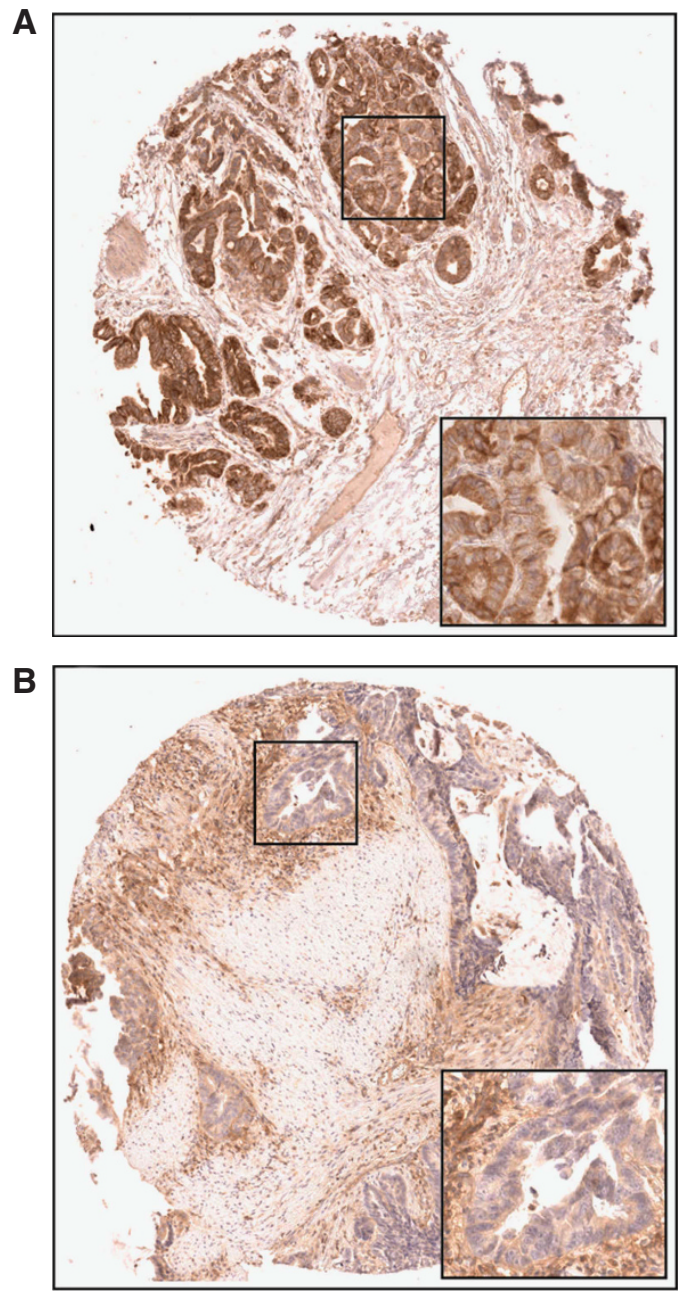

Figure 1. $\mathrm{MHC}$ I expression in BTC. Representative pictures of (A) strong $\mathrm{MHC}$ I expression and (B) weak $\mathrm{MHC}$ I expression in perihilar ECCs (original magnification: $50 \times$; inlet $200 \times$ ).

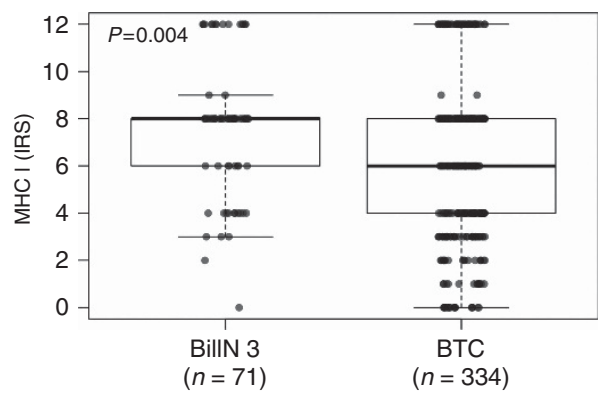

Figure 2. $\mathrm{MHC}$ I expression in pre-invasive intraepithelial neoplastic lesions (BillN 3) compared with invasive BTC. P-value calculated by Mann-Whitney U-test. 
compared with the respective corresponding invasive BTC confirmed the loss of MHC I in the evolution of an intraepithelial into an invasive neoplastic lesion. However, here the loss was only borderline significant, possibly because of the lower sample size $(P=0.066$; Supplementary Figure 2). Additionally evaluated samples of non-neoplastic biliary tract epithelia showed a higher MHC I expression compared to BilIN 3 lesions (data not shown).

Association of MHC I expression on tumour cells with clinicopathological variables in BTC. Analysis of MHC I expression with clinicopathological data revealed a trend for higher MHC I expression in lower UICC stages $(P=0.074$; Table 1). Furthermore, a significant association of high MHC I expression and low tumour grade could be observed $(P=0.05$; Table 1). Other clinicopathological variables did not show an association with MHC I expression (Table 1).

Correlation of MHC I expression on tumour cells with the density of tumour-infiltrating immune cells in BTC. Next, we investigated the association between MHC I expression on tumour cells and the density of specific immune cell types in the same cohort. We found that MHC I expression was associated with the number of tumour-infiltrating immune cells (Figures 3 and 4). However, the statistical strength of correlations varied. Correlation was strongest for $\mathrm{CD} 68^{+}$macrophages followed by $\mathrm{CD} 8^{+}$ T-lymphocytes and $\mathrm{CD}^{+}{ }^{+}$T-lymphocytes, whereas correlation with the density of $\mathrm{CD} 20^{+}$B-cells was only weak (Figure 4). In addition, MHC I expression did not correlate with the proliferation rate (number of Ki-67 positive tumour cells in percent) in BTC.

We then analysed the association of tumour-infiltrating immune cells and MHC I expression separately for the BTC subtypes. Thereby, we found that the associations between inflammatory infiltrates and MHC I expression observed in the whole cohort (see above) were also evident in ECC, whereas in ICC, MHC I expression was correlated significantly only with the number of tumour-infiltrating $\mathrm{CD} 8^{+}$T-lymphocytes; in GBAC, a significant correlation of MHC I expression was only seen for CD68+ macrophages (Supplementary Figures 3-5).
MHC I expression on tumour cells is an independent prognosticator of overall survival in BTC patients. Classical survival prognosticators such as UICC-stage proved to have high prognostic impact in our BTC cohort (Supplementary Table 1). Higher MHC I expression on tumour cells was also significantly associated with longer overall survival in BTC patients $(P=0.029$ and $P=0.006$, respectively; Figure 5). Although patients with low

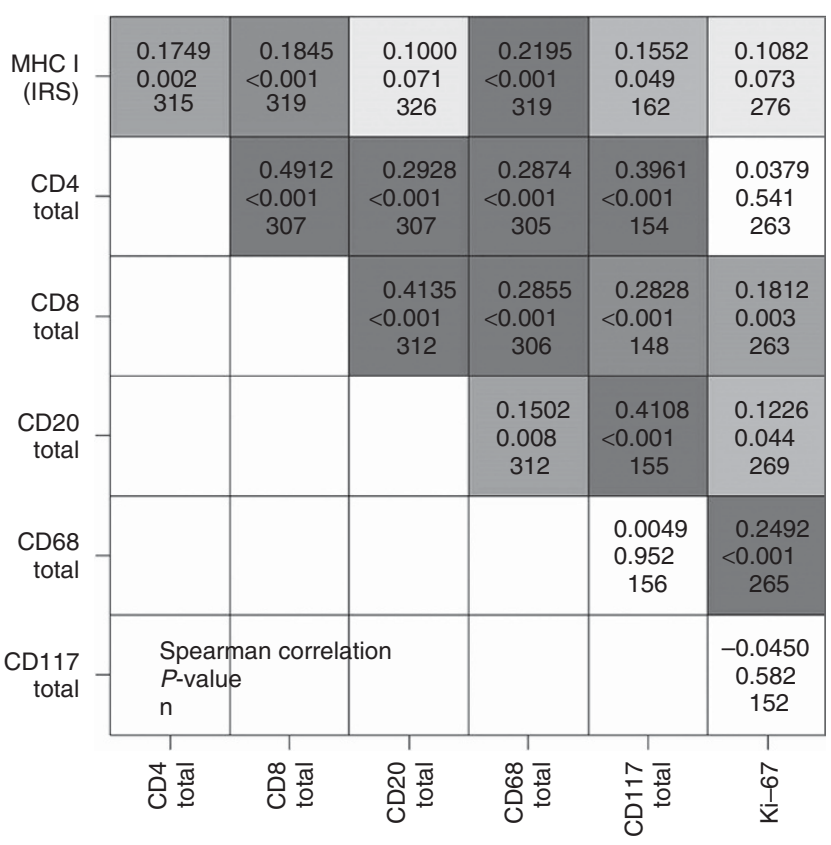

Figure 4. Spearman's rank correlation $\rho$ between density of inflammatory cell types, proliferation index (Ki-67) and $\mathrm{MHC}$ I expression in BTC. Levels of grey represent strength of correlation, with dark grey tones showing a high degree of association. In each square, there are three values given: top $=\rho$, middle $=P$-value, bottom $=$ sample size.

MHC I (IRS 0-4 vs 6-8 vs 9-12)

A

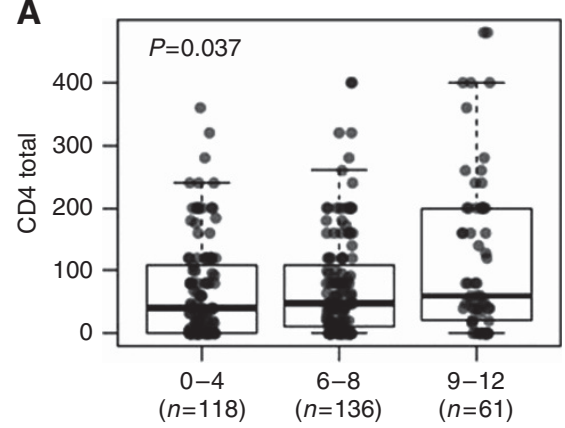

C

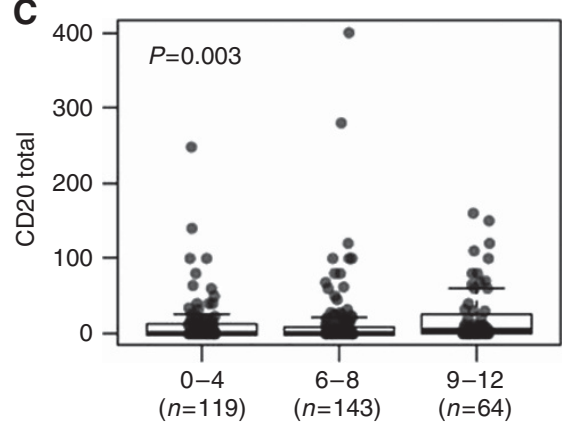

B

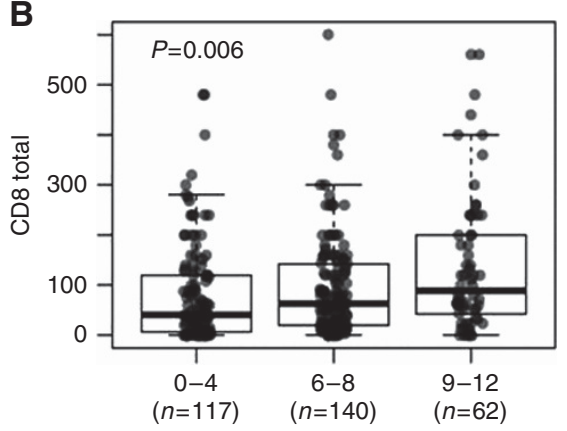

D

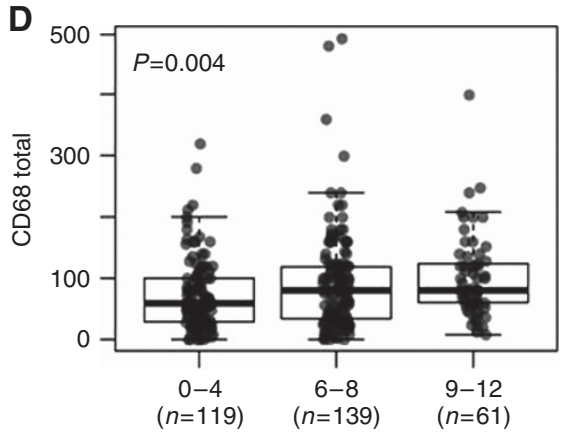

Figure 3. Correlation between inflammatory cells and MHC I expression in BTC. Y-axis: (A) CD4+ T-lymphocyte counts, (B) CD8+ T-lymphocyte counts, (C) CD20+ B-cell counts, (D) CD68+ macrophage counts. X-axis: MHC I expression. IRS=immunoreactive score. 

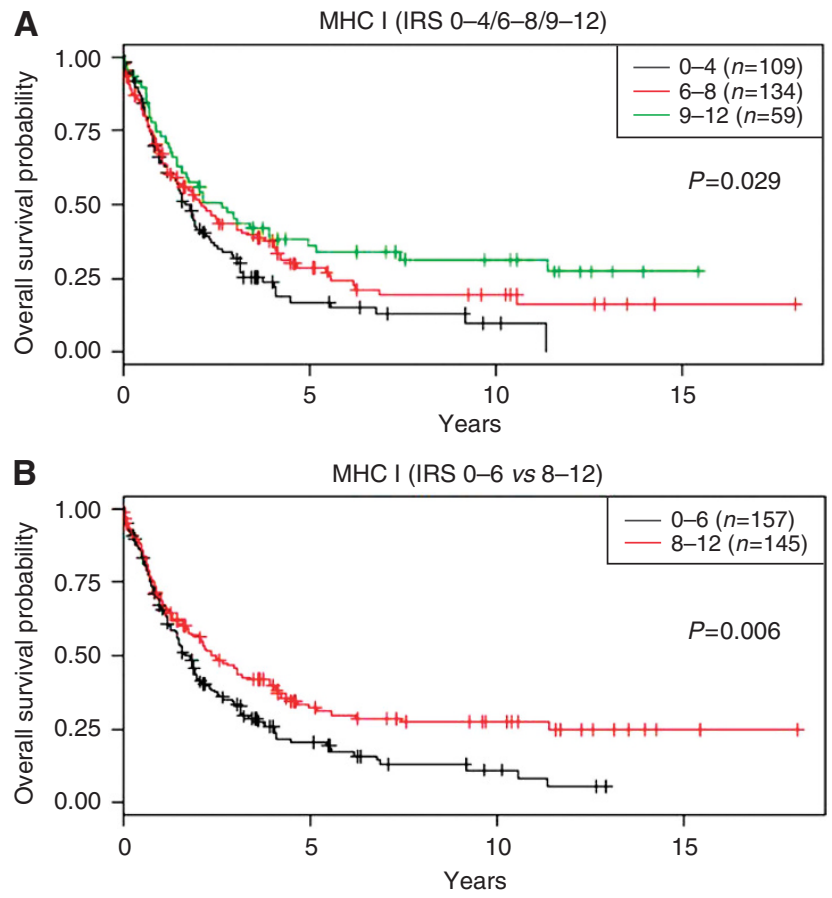

Figure 5. Overall survival probability in BTC patients stratified for MHC I expression. Kaplan-Meier curves depict overall survival probability stratified according to either $(\mathbf{A})$ a three-tier classification or (B) a two-tier classification of $\mathrm{MHC}$ I expression. P-values were calculated by log-rank test.

MHC I expression had a median survival of 20.01 months in our BTC cohort, patients exhibiting strong MHC I expression had an improved median overall survival of 28.06 months $(P=0.006)$. Multivariate analysis under inclusion of UICC-stage revealed a significant independent prognostic impact of MHC I expression in BTC (HR: 0.631, $P=0.02$; Table 2). Analysis of BTC subtypes showed that the prognostic significance of MHC I expression on tumour cells is by trend stronger in ECC and GBAC compared with ICC (Supplementary Figure 6).

\section{DISCUSSION}

In this study, we provide a comprehensive analysis of MHC I expression patterns in BTC. We used a previously described, large and well-characterized BTC cohort and could thereby correlate MHC I expression on tumour cells with the amount of specific cells of the tumour-infiltrating inflammatory infiltrate and patient prognosis.

A variety of functional data demonstrated that in the course of carcinogenesis neoplasms are able to acquire the ability to evade an activation of the adaptive immune response (Dunn et al, 2004; Rabinovich et al, 2007). This issue has been studied extensively in a variety of human cancers, including breast, prostate, pancreatic, oesophagus and colorectal cancer (Du and Wang, 2011; Scott et al, 2012). Concerning biliary malignancies and immune escape mechanisms, however, the number of available studies is limited (Que et al, 1999; Shimonishi et al, 2000; Norris et al, 2003).

One major mechanism of immune escape is downregulation of MHC I antigen on cancer cells which can take place as a consequence of a number of different molecular alterations (Seliger, 2008, 2012). Multiple molecular mechanisms, including epigenetic alterations, have been described as being responsible for MHC I downregulation (Koopman et al, 2000; Nie et al, 2001; Goeppert et al, 2014) and altered MHC I phenotypes have been described (Garrido et al, 1997; Cabrera et al, 2003). Downregulation
Table 2. Results of multivariate survival analysis under inclusion of MHC I expression and UICC-stage as exploratory factors for overall survival in BTC

\begin{tabular}{|c|c|c|c|c|}
\hline & HR & $\begin{array}{l}\text { Lower } \\
\mathrm{Cl}(95 \%)\end{array}$ & $\begin{array}{c}\text { Upper } \\
\text { Cl (95\%) }\end{array}$ & $P$-value \\
\hline MHC weak (IRS 0-4) & 1 & & & \\
\hline MHC moderate (IRS 6-8) & 0.875 & 0.641 & 1.195 & 0.4 \\
\hline MHC strong (IRS 9-12) & 0.661 & 0.442 & 0.989 & 0.04 \\
\hline UICC 1 & 1 & & & \\
\hline UICC 2 & 0.971 & 0.584 & 1.612 & 0.9 \\
\hline UICC 3 & 1.73 & 1.085 & 2.759 & 0.02 \\
\hline UICC 4 & 2.398 & 1.495 & 3.847 & $<0.001$ \\
\hline \multicolumn{5}{|l|}{ Total $(n=302)$} \\
\hline $\begin{array}{l}\text { Abbreviations: } \mathrm{BTC}=\text { biliary } \\
\text { IRS }=\text { immunoreactive score } \\
\mathrm{UICC}=\text { Union for Internatio } \\
\text { significance of individual fact }\end{array}$ & $\begin{array}{l}\text { ct canc } \\
\text { MHC } \\
\text { Cance } \\
\text { were ca }\end{array}$ & $\begin{array}{l}\mathrm{Cl}=\text { confide } \\
\text { major histo } \\
\text { Control. P-v } \\
\text { lated by Wal }\end{array}$ & $\begin{array}{l}\text { nterval; } H R= \\
\text { atibility comp } \\
\text { for testing }\end{array}$ & $\begin{array}{l}\text { azard ratio; } \\
\text { class ।; } \\
\text { statistical }\end{array}$ \\
\hline
\end{tabular}

of MHC I expression on cancer cells has been demonstrated in a variety of human malignancies and mostly, but not exclusively, had a negative impact on patient survival (Natali et al, 1989; Facoetti et al, 2005; Meissner et al, 2005; Ogino et al, 2006; Han et al, 2008; Kasajima et al, 2010; Du and Wang, 2011). In line with these studies, we here demonstrated that reduced MHC I expression in BTC is linked to shortened overall survival probability of patients.

Based on our current and previous data focusing on BTC subtypes, we hypothesise that in ICC interactions between tumour cells and immune system do not appear to strictly follow the classical pattern. On the one hand, no specific immune cell type was associated with an improved overall survival in ICC (Goeppert et al, 2013); on the other hand, MHC I expression in ICC exhibited less prognostic impact compared with ECC and GBAC. Accordingly, alternative mechanisms might play a more important role in the tumour-immune system interaction in ICC. These alternative mechanisms might include aberrant regulation of other factors of the antigen-processing machinery, or other potential mechanisms of tumour immune escape, such as Fas-mediated apoptosis of immune cells. In accordance with this, one study showed in ICC upregulation of FasL at early stages and downregulation of FasL at progressed stages, thereby indicating a potential role of this immune escape mechanism in cholangiocarcinogenesis (Shimonishi et al, 2000). Interestingly, in vitro experiments showed that primary and malignant cholangiocytes undergo CD40mediated Fas-dependent apoptosis, but are insensitive to direct activation with exogenous FasL (Humphreys et al, 2010). Taken together, the current data suggest that ICC is less sensitive to immune cell-mediated antitumour effects than ECC and GBAC.

In this study, we also investigated MHC I expression in preinvasive BilIN 3 and found higher expression levels compared with invasive BTC. Noteworthy, already BilIN 3 showed a downregulation of MHC I expression compared to non-neoplastic biliary tract epithelia. A decrease of MHC I expression in tumour-adjacent normal mucosa and in non-invasive intraepithelial neoplastic lesions has been previously noted in other cancer types (Kaklamanis et al, 1992; Tsioulias et al, 1992, 1993; Grandis et al, 2000). These data imply that in a variety of tumours loss of MHC I expression can act as an early onset mechanism of tumour immune escape, which might be effective in BTC as well. In addition, the prevalence of reversible (soft) and/or irreversible (hard) MHC I alterations has been proposed to have a major impact on the ability of T-lymphocytes to destroy malignant cells (Garrido et al, 2010). However, in this study we have not investigated specific mechanisms by which MHC I downregulation may be triggered in BTC.

We observed that MHC I expression on tumour cells is not only correlated with the number of tumour-infiltrating T-lymphocytes, but 
also with the amount of tumour-infiltrating macrophages. This interesting finding highlights the recently widely acknowledged importance of macrophages in the tumour-immune system interaction. However, in our experimental setting it is only speculative whether macrophages are attracted by chemokines produced by $\mathrm{T}$-lymphoctes or vice versa. The exact mechanisms that may underlie this association remain to be addressed in future functional studies. Nevertheless, macrophages may also play an important role in the tumour-immune system interaction in BTC, as it has been shown for other cancer types (Shimura et al, 2000; Kawai et al, 2008). However, intratumoural macrophage count was not associated with significant differences in overall survival in BTC (Goeppert et al, 2013) which indicates that macrophage density per se might not be of utmost importance in the antitumour immune response in this tumour type.

Recently, immune response-modulating targeted therapies have been very successfully tested as anticancer agents in a variety of human tumours. The first substance in this regard was Ipilimumab, a monoclonal antibody directed against cytotoxic $\mathrm{T}$ lymphocyte-associated antigen-4 (CTLA-4). Ipilimumab has been approved for therapy in malignant melanoma (Weber et al, 2008) and is under evaluation in a broad variety of other solid neoplasms (Kirkwood et al, 2012). Recently, several other even more promising- drugs, which block programmed death 1 protein (PD-1) and one of its ligands programmed death ligand 1 (PD-L1) have also been tested with respect to their antitumour activity and have been or will be approved for therapy in a variety of solid tumours, including non-small cell lung cancer and melanoma (Brahmer et al, 2015; Errico, 2015; Garon et al, 2015; Larkin et al, 2015). Consequently, the clinical effects of these drugs are now explored in other tumour entities as well. It is conceivable to speculate that the pre-existing density of inflammatory cells and the expression levels of MHC I on tumour cells might be connected to the response to immune modulation drugs.

In conclusion, we here report that MHC I expression in BTC is correlated with type and density of tumour-infiltrating immune cells. Furthermore, the loss of MHC I expression in tumour cells is associated with shortened overall survival in BTC patients. The respective associations were specifically strong in ECC, but considerably weaker in ICC, thereby pointing towards potentially therapy-relevant differences in immune escape mechanisms between BTC subtypes. These data provide a solid basis for a better understanding of the biological role of the regulation of antitumour inflammation in BTC, as well as for future functional and clinical studies investigating the modulation of the inflammatory response for the benefit of BTC patients.

\section{ACKNOWLEDGEMENTS}

We thank John Moyers (Institute of Pathology, University of Heidelberg) and the NCT tissue bank Heidelberg, in particular Veronika Geissler and Gloria Laukemper, for the support. This work was supported by a grant from the Deutsche Forschungsgemeinschaft (DFG) to PS (SFB/TRR77).

\section{CONFLICT OF INTEREST}

The authors declare no conflict of interest.

\section{REFERENCES}

Boon T, Cerottini JC, Van den Eynde B, van der Bruggen P, Van Pel A (1994) Tumour antigens recognized by T lymphocytes. Annu Rev Immunol 12: 337-365.
Bosman FT, Carneiro F, Hruban RH, Theise ND (2010) WHO Classification of Tumours of the Digestive System. 4th edn (International Agency for Research on Cancer (IARC).

Brahmer J, Reckamp KL, Baas P, Crino L, Eberhardt WE, Poddubskaya E, Antonia S, Pluzanski A, Vokes EE, Holgado E, Waterhouse D, Ready N, Gainor J, Aren Frontera O, Havel L, Steins M, Garassino MC, Aerts JG, Domine M, Paz-Ares L, Reck M, Baudelet C, Harbison CT, Lestini B, Spigel DR (2015) Nivolumab versus Docetaxel in advanced squamous-cell non-small-cell lung cancer. N Engl J Med 373(2): 123-135.

Cabrera T, Lopez-Nevot MA, Gaforio JJ, Ruiz-Cabello F, Garrido F (2003) Analysis of HLA expression in human tumour tissues. Cancer Immunol Immunother 52(1): 1-9.

Campoli M, Ferrone S (2008) HLA antigen changes in malignant cells: epigenetic mechanisms and biologic significance. Oncogene 27(45): 5869-5885.

Du C, Wang Y (2011) The immunoregulatory mechanisms of carcinoma for its survival and development. J Exp Clin Cancer Res 30: 12.

Dunn GP, Old LJ, Schreiber RD (2004) The three Es of cancer immunoediting. Annu Rev Immunol 22: 329-360.

Errico A (2015) Melanoma: CheckMate 067-frontline nivolumab improves PFS alone or in combination with ipilimumab. Nat Rev Clin Oncol 12(8): 435.

Facoetti A, Nano R, Zelini P, Morbini P, Benericetti E, Ceroni M, Campoli M, Ferrone S (2005) Human leukocyte antigen and antigen processing machinery component defects in astrocytic tumours. Clin Cancer Res 11(23): 8304-8311.

Fukunaga A, Miyamoto M, Cho Y, Murakami S, Kawarada Y, Oshikiri T, Kato K, Kurokawa T, Suzuoki M, Nakakubo Y, Hiraoka K, Itoh T, Morikawa T, Okushiba S, Kondo S, Katoh H (2004) CD8 + tumourinfiltrating lymphocytes together with $\mathrm{CD} 4+$ tumour-infiltrating lymphocytes and dendritic cells improve the prognosis of patients with pancreatic adenocarcinoma. Pancreas 28(1): e26-e31.

Galon J, Costes A, Sanchez-Cabo F, Kirilovsky A, Mlecnik B, Lagorce-Pages C, Tosolini M, Camus M, Berger A, Wind P, Zinzindohoue F, Bruneval P, Cugnenc PH, Trajanoski Z, Fridman WH, Pages F (2006) Type, density, and location of immune cells within human colorectal tumours predict clinical outcome. Science 313(5795): 1960-1964.

Garon EB, Rizvi NA, Hui R, Leighl N, Balmanoukian AS, Eder JP, Patnaik A, Aggarwal C, Gubens M, Horn L, Carcereny E, Ahn MJ, Felip E, Lee JS, Hellmann MD, Hamid O, Goldman JW, Soria JC, Dolled-Filhart M, Rutledge RZ, Zhang J, Lunceford JK, Rangwala R, Lubiniecki GM, Roach C, Emancipator K, Gandhi L. Investigators K- (2015) Pembrolizumab for the treatment of non-small-cell lung cancer. N Engl J Med 372(21): 2018-2028.

Garrido F, Cabrera T, Aptsiauri N (2010) 'Hard' and 'soft' lesions underlying the HLA class I alterations in cancer cells: implications for immunotherapy. Int J Cancer 127(2): 249-256.

Garrido F, Ruiz-Cabello F, Cabrera T, Perez-Villar JJ, Lopez-Botet M, Duggan-Keen M, Stern PL (1997) Implications for immuno surveillance of altered HLA class I phenotypes in human tumours. Immunol Today 18(2): 89-95.

Goeppert B, Frauenschuh L, Zucknick M, Stenzinger A, Andrulis M, Klauschen F, Joehrens K, Warth A, Renner M, Mehrabi A, Hafezi M, Thelen A, Schirmacher P, Weichert W (2013) Prognostic impact of tumour-infiltrating immune cells on biliary tract cancer. Br J Cancer 109(10): 2665-2674.

Goeppert B, Konermann C, Schmidt CR, Bogatyrova O, Geiselhart L, Ernst C, Gu L, Becker N, Zucknick M, Mehrabi A, Hafezi M, Klauschen F, Stenzinger A, Warth A, Breuhahn K, Renner M, Weichert W, Schirmacher P, Plass C, Weichenhan D (2014) Global alterations of DNA methylation in cholangiocarcinoma target the Wnt signaling pathway. Hepatology 59(2): 544-554.

Goeppert B, Schmezer P, Dutruel C, Oakes C, Renner M, Breinig M, Warth A, Vogel MN, Mittelbronn M, Mehrabi A, Gdynia G, Penzel R, Longerich T, Breuhahn K, Popanda O, Plass C, Schirmacher P, Kern MA (2010) Downregulation of tumour suppressor A kinase anchor protein 12 in human hepatocarcinogenesis by epigenetic mechanisms. Hepatology 52(6): 2023-2033. Grandis JR, Falkner DM, Melhem MF, Gooding WE, Drenning SD, Morel PA (2000) Human leukocyte antigen class I allelic and haplotype loss in squamous cell carcinoma of the head and neck: clinical and immunogenetic consequences. Clin Cancer Res 6(7): 2794-2802.

Han LY, Fletcher MS, Urbauer DL, Mueller P, Landen CN, Kamat AA, Lin YG, Merritt WM, Spannuth WA, Deavers MT, De Geest K, Gershenson DM, Lutgendorf SK, Ferrone S, Sood AK (2008) HLA class I antigen processing machinery component expression and intratumoural T-Cell infiltrate as independent prognostic markers in ovarian carcinoma. Clin Cancer Res 14(11): 3372-3379. 
Hezel AF, Deshpande V, Zhu AX (2010) Genetics of biliary tract cancers and emerging targeted therapies. J Clin Oncol 28(21): 3531-3540.

Humphreys EH, Williams KT, Adams DH, Afford SC (2010) Primary and malignant cholangiocytes undergo CD40 mediated Fas dependent apoptosis, but are insensitive to direct activation with exogenous Fas ligand. PLoS One 5(11): e14037.

Kaklamanis L, Gatter KC, Hill AB, Mortensen N, Harris AL, Krausa P, McMichael A, Bodmer JG, Bodmer WF (1992) Loss of HLA class-I alleles, heavy chains and beta 2-microglobulin in colorectal cancer. Int J Cancer 51(3): 379-385.

Kasajima A, Sers C, Sasano H, Johrens K, Stenzinger A, Noske A, Buckendahl AC, Darb-Esfahani S, Muller BM, Budczies J, Lehman A, Dietel M, Denkert C, Weichert W (2010) Down-regulation of the antigen processing machinery is linked to a loss of inflammatory response in colorectal cancer. Hum Pathol 41(12): 1758-1769.

Kawai O, Ishii G, Kubota K, Murata Y, Naito Y, Mizuno T, Aokage K, Saijo N, Nishiwaki Y, Gemma A, Kudoh S, Ochiai A (2008) Predominant infiltration of macrophages and CD8 $(+)$ T Cells in cancer nests is a significant predictor of survival in stage IV nonsmall cell lung cancer. Cancer 113(6): 1387-1395.

Kirkwood JM, Butterfield LH, Tarhini AA, Zarour H, Kalinski P, Ferrone S (2012) Immunotherapy of cancer in 2012. CA Cancer J Clin 62(5): 309-335.

Koopman LA, Corver WE, van der Slik AR, Giphart MJ, Fleuren GJ (2000) Multiple genetic alterations cause frequent and heterogeneous human histocompatibility leukocyte antigen class I loss in cervical cancer. J Exp Med 191(6): 961-976.

Larkin J, Lao CD, Urba WJ, McDermott DF, Horak C, Jiang J, Wolchok JD (2015) Efficacy and safety of nivolumab in patients with BRAF V600 mutant and BRAF wild-type advanced melanoma: a pooled analysis of 4 clinical trials. JAMA Oncol 1(4): 433-440.

Mahmoud SM, Paish EC, Powe DG, Macmillan RD, Grainge MJ, Lee AH, Ellis IO, Green AR (2011) Tumour-infiltrating CD8 + lymphocytes predict clinical outcome in breast cancer. J Clin Oncol 29(15): 1949-1955.

Meissner M, Reichert TE, Kunkel M, Gooding W, Whiteside TL, Ferrone S, Seliger B (2005) Defects in the human leukocyte antigen class I antigen processing machinery in head and neck squamous cell carcinoma: association with clinical outcome. Clin Cancer Res 11(7): 2552-2560.

Mlecnik B, Tosolini M, Kirilovsky A, Berger A, Bindea G, Meatchi T, Bruneval P, Trajanoski Z, Fridman WH, Pages F, Galon J (2011) Histopathologicbased prognostic factors of colorectal cancers are associated with the state of the local immune reaction. J Clin Oncol 29(6): 610-618.

Natali PG, Nicotra MR, Bigotti A, Venturo I, Marcenaro L, Giacomini P, Russo C (1989) Selective changes in expression of HLA class I polymorphic determinants in human solid tumours. Proc Natl Acad Sci USA 86(17): 6719-6723.

Nie Y, Yang G, Song Y, Zhao X, So C, Liao J, Wang LD, Yang CS (2001) DNA hypermethylation is a mechanism for loss of expression of the HLA class I genes in human esophageal squamous cell carcinomas. Carcinogenesis 22(10): 1615-1623.

Norris S, Doherty DG, Curry M, McEntee G, Traynor O, Hegarty JE, O'Farrelly C (2003) Selective reduction of natural killer cells and T cells expressing inhibitory receptors for MHC class I in the livers of patients with hepatic malignancy. Cancer Immunol Immunother 52(1): 53-58.

Ogino T, Shigyo H, Ishii H, Katayama A, Miyokawa N, Harabuchi Y, Ferrone S (2006) HLA class I antigen down-regulation in primary laryngeal squamous cell carcinoma lesions as a poor prognostic marker. Cancer Res 66(18): 9281-9289.
Patel T (2011) Cholangiocarcinoma-controversies and challenges. Nat Rev Gastroenterol Hepatol 8(4): 189-200.

Que FG, Phan VA, Phan VH, Celli A, Batts K, LaRusso NF, Gores GJ (1999) Cholangiocarcinomas express Fas ligand and disable the Fas receptor. Hepatology 30(6): 1398-1404.

Rabinovich GA, Gabrilovich D, Sotomayor EM (2007) Immunosuppressive strategies that are mediated by tumour cells. Annu Rev Immunol 25: 267-296.

Rodriguez T, Aptsiauri N, Mendez R, Jimenez P, Ruiz-Cabello F, Garrido F (2007) Different mechanisms can lead to the same altered HLA class I phenotype in tumours. Tissue Antigens 69(Suppl 1): 259-263.

Ryschich E, Notzel T, Hinz U, Autschbach F, Ferguson J, Simon I, Weitz J, Frohlich B, Klar E, Buchler MW, Schmidt J (2005) Control of T-cellmediated immune response by HLA class I in human pancreatic carcinoma. Clin Cancer Res 11(2 Pt 1): 498-504.

Scott AM, Wolchok JD, Old LJ (2012) Antibody therapy of cancer. Nat Rev Cancer 12(4): 278-287.

Seliger B (2008) Molecular mechanisms of MHC class I abnormalities and APM components in human tumours. Cancer Immunol Immunother 57(11): 1719-1726.

Seliger B (2012) Novel insights into the molecular mechanisms of HLA class I abnormalities. Cancer Immunol Immunother 61(2): 249-254.

Shimonishi T, Isse K, Shibata F, Aburatani I, Tsuneyama K, Sabit H, Harada K, Miyazaki K, Nakanuma Y (2000) Up-regulation of fas ligand at early stages and down-regulation of Fas at progressed stages of intrahepatic cholangiocarcinoma reflect evasion from immune surveillance. Hepatology 32(4 Pt 1): 761-769.

Shimura S, Yang G, Ebara S, Wheeler TM, Frolov A, Thompson TC (2000) Reduced infiltration of tumour-associated macrophages in human prostate cancer: association with cancer progression. Cancer Res 60(20): $5857-5861$.

Smyth MJ, Dunn GP, Schreiber RD (2006) Cancer immunosurveillance and immunoediting: the roles of immunity in suppressing tumour development and shaping tumour immunogenicity. Adv Immunol 90: $1-50$.

Tsioulias G, Godwin TA, Goldstein MF, McDougall CJ, Ngoi SS, DeCosse JJ, Rigas B (1992) Loss of colonic HLA antigens in familial adenomatous polyposis. Cancer Res 52(12): 3449-3452.

Tsioulias GJ, Triadafilopoulos G, Goldin E, Papavassiliou ED, Rizos S, Bassioukas P, Rigas B (1993) Expression of HLA class I antigens in sporadic adenomas and histologically normal mucosa of the colon. Cancer Res 53(10 Suppl): 2374-2378.

Weber JS, O’Day S, Urba W, Powderly J, Nichol G, Yellin M, Snively J, Hersh E (2008) Phase I/II study of ipilimumab for patients with metastatic melanoma. J Clin Oncol 26(36): 5950-5956.

Zhang L, Conejo-Garcia JR, Katsaros D, Gimotty PA, Massobrio M, Regnani G, Makrigiannakis A, Gray H, Schlienger K, Liebman MN, Rubin SC, Coukos G (2003) Intratumoural T cells, recurrence, and survival in epithelial ovarian cancer. N Engl J Med 348(3): 203-213.

This work is published under the standard license to publish agreement. After 12 months the work will become freely available and the license terms will switch to a Creative Commons AttributionNonCommercial-Share Alike 4.0 Unported License.

Supplementary Information accompanies this paper on British Journal of Cancer website (http://www.nature.com/bjc) 